\title{
2001-2015 DÖNEMINDE UYGULANAN PARA POLITIKALARININ “KIRILGAN BEŞLI” ÜLKELERI ÜZERINDEKI ETKILERI*
}

\author{
Ayşe Özge ARTEKIN** \\ Haldun SOYDAL ***
}

\section{ÖZET}

2013’te Morgan Stanley'in yayınlamış olduğu raporda Brezilya, Endonezya, Güney Afrika, Hindistan ve Türkiye'nin olduğu beş ülke "Kırılgan Beşli” ülkeleri olarak adlandırılmıştır. Bu gruplandırmanın esas nedenleri ise ülkelerin enflasyon oranları, büyüme oranları ve cari açıkları sebebiyle para birimlerinin 2013 yılında ABD Doları karşısında aşırı değer kaybetmeleridir. Bu nedenler finansal kırılganlığın ölçülmesi ve makroekonomik istikrarın sağlanması açısından bütün ülkeler için oldukça önemlidir. Çalışmada iç ve dış şoklara karşı kırılgan ülkeler çeşitli ekonomik göstergelerle incelenmiş ve Türkiye ekonomisinin de dâhil olduğu "Kırılgan Beşli" gruplamasında Türkiye'nin ekonomik yapısı, ekonomik göstergelerin yardımı ile analiz edilmiştir.

\footnotetext{
* Bu makale, Doç. Dr. Haldun SOYDAL'ın danışmanlığında hazırlanmış olan "2008 Küresel Finans Krizi Sonrası Uygulanan Para Politikaları ve Gelişmekte Olan Bazı Ülkelere Etkileri" başlıklı yüksek lisans tez çalışmasından yararlanılarak üretilmiştir.

** Selçuk Üniversitesi Sosyal Bilimler Enstitüsü İktisat Anabilim Dalı Doktora Öğrencisi.

*** Doç. Dr., Selçuk Üniversitesi İ̈BF İktisat Bölümü Öğretim Üyesi.
} 


\section{ABSTRACT}

In 2013, the five countries in which Brazil, India, Indonesia, South Africa and Turkey are called as the "Fragile Five" countries by Morgan Stanley's report. The main reasons for this because grouping is that of inflation rates, growth rates and current account deficits troubled emerging market currencies of countries were reduced in value against U.S. Dollar in 2013. This reasons are extremely important for all countries, on account of measurement of financial fragility and provide the macro-economic stability. In the study, fragile countries against internal and external shocks were examined with various economic indicators and including the Turkey economy in the group of "Fragile Five" with the help of economic indicators, analyzing of Turkey's economic structure.

\section{GİRIŞ}

Para, günlük hayattaki ekonomik işlevleri kolaylaştırmak amacıyla ortaya çıkan ancak hareketli bir yapıya sahip olması sebebiyle daimi olarak değişim ve gelişim gösteren bir araçtır. Gelişmiş ve gelişmekte olan tüm ülke ekonomilerinde genel ekonomik istikrarı sağlamak amacıyla para, bir politika aracı olarak kullanılmaktadır. Para miktarının kontrolü yoluyla uygulanan bu politikada, bir takım araçlar kullanılmaktadır ki, para politikası olarak nitelendirilen araçlar, günümüz ekonomilerinde yaygın biçimde kullanılmaktadır.

Dünyada, gerek iktisatçılar gerekse de merkez bankası tarafindan görüş birliğine varılan konu; para politikasının en önemli aracının fiyat istikrarı oluşudur. Dolayısıyla para politikalarıyla fiyat istikrarını sağlamaya yönelik stratejiler izlenmektedir. Para politikasının en önemli tartışma konusu ise enflasyonist yönelimin çözümüne dair önerilerdir. 1970'li ve 1980'li yıllarda uygulanan para politikalarının, istihdamın ve hasılanın sürdürülebilirliğini sağlayamaması, para otoritelerini yeni politikalar bulmaya yöneltmiştir.

Döviz kuru hedeflemesi ve parasal hedeflemenin dünya genelinde başarısızlığa neden olması da ülkeleri yeni para politikaları geliştirmeye zorlamıştır. Enflasyon hedeflemesi rejimi bu dönemde ortaya çıkan bir strateji olmuştur.

Küreselleşme ile birlikte dış ekonomik ilişkiler sebebiyle belirli riskler oluşmaktadır. $\mathrm{Bu}$ risklerden korunmak içinekonominin dışa kapalı olması gereklidir. Ancak küreselleşen dünyada dışa kapalı bir ekonomi modeli uygulamak zor olmaktadır. Dışarıya bağımlı olan ülkelerin finansman ihtiyaçlarının yüksek düzeyde oluşu o ülkelerin ekonomilerini dışsal olarak daha kırılgan yapmaktadır. Bu kırılganlık yabancı yatırımcılar için önemli bir göstergedir. Yatırımcılar, yatırım için getirdikleri dövizi, vade sonunda getirisiyle birlikte geri almak istemektedirler. Bu durum yatırım yapılmak istene ülkenin göstergelere bakarak analiz edilebilmektedir (Çan ve Dinçsoy, 2016: 202).

Kırılgan beşli olarak adlandırılan gruplandırma ise ABD Merkez Bankası'nın (FED) tahvil alımlarını azaltacağına yönelik yaptığı açıklamadan sonra oluşmuştur. FED'in açıklamasının ardından paraları en çok değer kaybeden yükselen piyasa ekonomileri Brezilya, Hindistan, Endonezya, Güney Afrika ve Türkiye olmuştur. Bu ülkelerin böyle bir grubun içinde değerlendirilmesinin sebepleri olarak cari açı̆̆ın GSYİH’ye oranının yüksek oluşu, büyüme performansındaki düşüşler ve yüksek enflasyon oranları gösterilmektedir (http://www.mahfiegilmez.com/2013/11/krlgan-besli.html). Erişim: 10. 07.2016.

Kırılgan beşli kategorisi içerisinde yer alan bu ülkeleri makroekonomik açıdan zor durumda bırakan en önemli husus cari açıktır. FED'in Küresel Finans Krizi sonrasında parasal genişleme politikası uygulamalarından sonra güçlü büyüme ve yatırım potansiyellerinden dolayı yüksek miktarda 
yabancı sermaye çekerek paraları hızla değerlenen ülkeler, aynı zamandaFED'in parasal sıkılaştırma politikasından en fazla etkilenen ülkeler olmuşlardır. Cari açığın finanse edilmesinin kolay olduğu dönemde cari açığın artmasına müdahale etmeyen bu ülkeler FED'in sıkı para politikası kararıyla birlikte cari açıklarının finansmanı konusunda tedbirler almaya zorlanmaktadırlar. Dolayısıyla, cari açık kırılganlaşma tartışmalarındaki en uygun makroekonomik tez durumundadır (Gür, 2014: 4).

Tablo 1: Kırılgan Beşli Ülkelerinin Cari Açı/GSYİH Oranları

\begin{tabular}{|l|l|l|l|l|l|l|l|l|lll|}
\hline & $\mathbf{2 0 0 5}$ & $\mathbf{2 0 0 6}$ & $\mathbf{2 0 0 7}$ & $\mathbf{2 0 0 8}$ & $\mathbf{2 0 0 9}$ & $\mathbf{2 0 1 0}$ & $\mathbf{2 0 1 1}$ & $\mathbf{2 0 1 2}$ & $\mathbf{2 0 1 3}$ & $\mathbf{2 0 1 4}$ & $\mathbf{2 0 1 5}$ \\
\hline BREZILYA & 1,8 & 1,3 & 0,1 & $-1,7$ & $-1,5$ & $-2,1$ & $-2,0$ & $-2,2$ & $-3,4-3,9$ & $-3,3$ \\
\hline HINNDISTTAN & $-1,6$ & $-1,0$ & $-1,3$ & $-2,3$ & $-2,8$ & $-2,7$ & $-4,2$ & $-4,7$ & $-1,7$ & $-1,4$ & $-1,1$ \\
\hline ENDONEZYA & 0,1 & 2,6 & 1,4 & 0,0 & 1,8 & 0,7 & 0,2 & $-2,7$ & $-3,2-3,0$ & $-2,1$ \\
\hline GÜNEY AFRİKA & $-3,6$ & $-5,3$ & $-7,0$ & $-7,2$ & $-4,0$ & $-2,0$ & $-2,3$ & $-5,2$ & $-5,8$ & $-5,4$ & $-4,3$ \\
\hline TÜRKIYE & $-4,3$ & $-6,0$ & $-5,8$ & $-5,5$ & $-2,0$ & $-6,2$ & $-9,7$ & $-6,2$ & $-7,9$ & $-5,7$ & $-4,5$ \\
\hline
\end{tabular}

Kaynak: World Bank, IMF

Tabloda incelenen kırılgan beşlinin cari açı/GSYIH oranında en kırılgan ülkenin Türkiye olduğu ve 2011 yılında oranının \%10'a yaklaştığı görülmektedir. Bu oran daha sonra gerilemeye başlamış olsa da hala yeterli seviyede değildir.

Türkiye'de enerji gereksiniminin büyük bölümünün dışarıdan karşılanması, yarı mamul mal ithalatı ve halkın yabancı ürün isteği cari açığın yüksek olmasının en büyük sebepleri arasında yer almaktadır. Türkiye'den sonra cari açığın GSYİH oranında yüksek kırılganlığa sahip olan ikinci ülke Güney Afrika'dır. 2012 ve 2014 yılları arasındabu ülkenin oranlarının \%5'in üzerinde olduğu ve risk oluşturduğu görülmektedir. Endonezya ve Brezilya'da ise oranların diğer ülkelere nazaran biraz daha düşük gerçekleştiği ve sürdürülebilir boyutta olduğu söylenebilir. İncelenen dönem içerisinde Endonezya'da oranın en yüksek değere sahip olduğu yıl 2013'tür ve bu oran \%3,2 seviyesindedir. Brezilya'daen yüksek değer \%3,9 ile 2014 yllında gözlemlenmektedir. Hindistan'da ise cari açık/GSYİH 2011-2012 yıllarında \%4'ten yüksek seviyede gerçekleşmiş fakat 2013 yılında \%1,7'ye, 2014 'te 1,4 'e2015'te ise 1,1'e düşmektedir. Ve bu oranlarla 2013 ve 2015 yılları arasında kırılgan beşli ülkeleri arasında en iyi konumdaki ülke Hindistan olmuştur (Çan ve Dinçsoy, 2016: 202).

Tablo 2: Kırılgan Beşli Ülkelerinin Büyüme Oranları

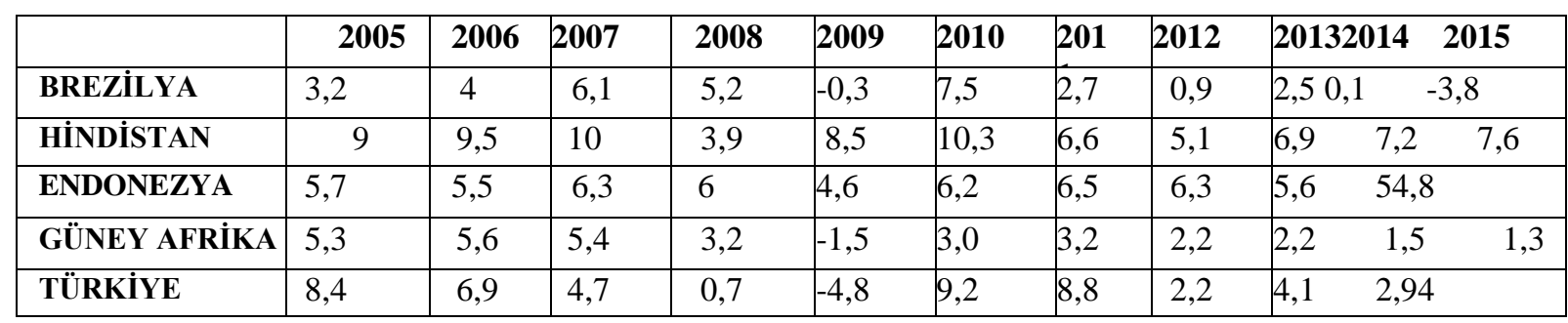

Kaynak: IMF 
Tabloya bakıldığında krizden sonra yaşanan büyümenin en fazla olduğu ülkenin Hindistan olduğu görülmektedir. Ardından ise Endonezya gelmektedir. Bu sıralamada en sonuncu ülke ise Güney Afrika'dır. Kırılgan beşli ülkeleri arasında kriz sonrası en fazla büyüme oranına yine Hindistan sahiptir.

Cari açık ile büyüme arasında şöyle bir ilişki bulunmaktadır. Cari açıkta bir daralma düşük ekonomik büyümelere neden olurken cari açıktaki büyüme ise ekonomik büyümeye destek verir niteliktedir (Freund, 2005:1282). Cari açığın yüksek olması ve büyümenin yavaşlaması krizlere karşı ülkeleri daha kırılgan hale getirmektedir (Bussiere ve Fraztcher, 2006: 958).

Tablo 3: Kırılgan Beşli Ülkelerinin Enflasyon Oranları

\begin{tabular}{|c|c|c|c|c|c|c|c|c|c|c|c|}
\hline & 2005 & 2006 & 2007 & 2008 & 2009 & 2010 & 2011 & 2012 & \multicolumn{3}{|c|}{201320142015} \\
\hline BREZÍLYA & 6,9 & 4,2 & 3,6 & 5,7 & 4,9 & 5 & 6,6 & 5,4 & 6,2 & 6,3 & 9 \\
\hline HİNDISTTAN & 4,2 & 6,1 & 6,4 & 8,4 & 10,9 & 12 & 8,9 & 9,3 & 10,9 & 6 & 4,9 \\
\hline ENDONEZYA & 10,5 & 13,1 & 6,4 & 9,8 & 4,8 & 5,1 & 5,3 & 4,3 & 6,4 & 6,4 & 6,4 \\
\hline GÜNEY AFRİKA & 3,4 & 4,6 & 7,1 & 11,5 & 7,1 & 4,2 & 5 & 5,7 & 5,5 & 6,4 & 4,6 \\
\hline TÜRKIIYE & 7,7 & 9,6 & 8,8 & 10,4 & 6,3 & 8,6 & 6,5 & 8,9 & 7,5 & 8,87 & \\
\hline
\end{tabular}

Kaynak: IMF

Tablo incelendiğinde en iyi enflasyon değerlerinin Brezilya'da olduğu görülmektedir (2015 yılı hariç). Brezilya bu değerleri uyguladığı yüksek reel faiz politikasına borçludur. Endonezya'nın ve Türkiye'nin özellikle bazı senelerdeki yüksek enflasyon oranının sebebi reel sektörün üretim gücünün zayif olmasidır.

Küresel Kriz sonrasında bu ülkelerde; yurtiçi likidite kolaylığı, politika faiz oranlarında değişiklik, döviz kuru müdahalesi zorunlu karşıllk oranlarının değiştirilmesi gibi birçok politika tedbirleri alınmıştır. Bu politika ve tedbirler daha detaylı incelendiğinde alınan tedbirlerin para politikası alanında yoğunlaştığını görülmektedir.

Kırılgan Beşli ülkelerinde, FED'in izlediği para politikası değişiklikleri ve sermaye çıkışlarının döviz kurları üzerindeki hakimiyeti enflasyonist süreç üzerinde etkili olmaktadır. Döviz kuru değişikleri tüketici fiyatlarına etki etmektedir ve döviz kuru hedeflemesi para politikası aktarım kanallarının en önemlileri arasındadır (IFF, 2014). Ancak artık döviz kurlarını spekülatif tehditlerden korumak zorlaşmışıı ve bu durum güvenirliğini azaltmaktadır. Ayrıca döviz kuru hedeflemesi bağımsız para politikası uygulamasını engellemekte ve dışsal şoklara karşı müdahale edilmesinde sıkıntı vermektedir. Bu yüzden bu politikanın tercih edilme sayısı gittikçe azalmaktadır (Mishkin, 2006: 13).

\section{Türkiye Üzerine İncelemeler}

Dışa karşı o dönemin en kırılgan ülkeleri arasında olan Türkiye, 2008 yılı sonlarında TCMB tarafından parasal genişleme sürecini başlatmıştır. Gelişmekte olan ülkelerin krize karşı verdikleri tepkiler baz alındığında en erken faiz indirimi politikası uygulayan ülkeler arasındadır. 2009 yılının ikinci yarısında dünya genelinde ekonomiler toparlanmaya başlasa da belirsizlikler hala hükmünü sürdürmektedir. Buna karşıllk TCMB, faiz indirimine devam etmiş ve 2008-2012 yılları arasında 
politika faizlerini yaklaşı 10 puan indirmiştir. Bu dönemde dünya genelinde enflasyon uygulaması yapan ülkeler arasında en fazla faiz indirimi yapan ülke olmuştur (Vural; 2013: 58). Diğer taraftan gelişmiş ülkelerde daha önce görülmemiş düzeyde parasal genişleme uygulama politikasıfiyat istikrarını sağlamada kolaylık sağlayarak, finansal istikrarın önemini arttırmıştır (Özer, 2014: 87).

TCMB iletişimi kolaylaştırmak amacıyla krediler ve döviz kuru olmak üzere iki değişken üzerine yoğunlaşmıştır. Bu değişkenlerin kolay gözlemlenebilmesi, gecikmeden açıklanması ve nihai araçlarla doğrudan etkileşiminin kurulabilmesi uygulanan politikanın iletişiminin daha sağlıklı yapılabilmesine olanak vermiştir. İletişimin krediler ve döviz kuru üzerinden yapılması, finansal istikrarında içinde olduğu nihai tablonun anlaşılmasını kolaylaştırması açısından önemli hale gelmektedir (Kara, 2012: 7).

Küresel Kriz'in derinleştiği dönemlerde Merkez Bankası tarafından piyasalara oldukça fazla likidite sağlanmıştır. Çıkış stratejisi çerçevesinde, bu fazla likiditenin geri alınması için 2010 yılının son çeyreğinde Türk Lirası zorunlu karşılık oranları kademeli olarak arttırılarak \%5'ten \%6'ya yükseltilmiştir. Yine bu dönemlerde zorunlu karşılık aracının daha etkili bir şekilde kullanımını sağlamak amacıyla zorunlu karşılıklara ödenen faizler kaldırılmıştır (Özer, 2014: 90). 
Tablo4: TCMB'nin Krizden Çıkış Stratejisi Doğrultusunda Uyguladığı Para Politikası

\begin{tabular}{|c|c|c|}
\hline Tarih & Kullanılan Politika Aracı & Politikanın Amacı \\
\hline $\begin{array}{l}\text { Nisan, Temmuz, Eylül } \\
2010\end{array}$ & $\begin{array}{l}\text { 1Yabancı para zorunlu karşıllik oranı toplamda } 2 \text { puan } \\
\text { artırılarak \%11 'e yükselmiştir. }\end{array}$ & Kredi piyasalarındaki genişlemeyi sınırlamak \\
\hline & $\begin{array}{l}\text { Esnek bir döviz alım ihale yöntemi benimsenerek } \\
\text { döviz alımları kolaylaştırılmıştır. } 2010 \text { yılında toplam } \\
14.1 \text { milyar ABD doları piyasadan alınmıştır. }\end{array}$ & $\begin{array}{l}\text { Türkiye'ye yönelik sermaye girişlerinin daha } \\
\text { istikrarlı hale getirilmesi ve TCMB rezerv } \\
\text { birikiminin beslenmesi }\end{array}$ \\
\hline Ekim 2010 & $\begin{array}{l}\text { Türk lirası zorunlu karşıllı oranları vadelere göre } \\
\text { farklılaştırılmış ve daha önce zorunlu karşılığa tabi } \\
\text { olmayan yurt içi ve yurt dışı repo işlemlerinden } \\
\text { sağlanan bazı fonlar da zorunlu karşılık kapsamına } \\
\text { alınmıştır. }\end{array}$ & 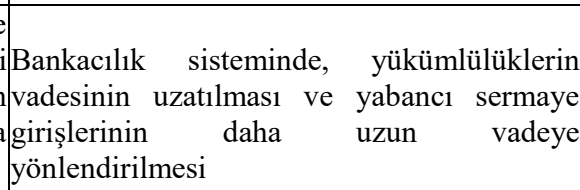 \\
\hline Ekim 2010 & $\begin{array}{l}\text { TCMB Döviz Depo Piyasasındaki aracılık işlemlerine } \\
\text { son vermiştir. Bununla birlikte, bankaları kendilerine } \\
\text { tanınan borçlanma limitleri çerçevesinde Merkez } \\
\text { Bankası'ndan alacakları döviz depo işlemlerinin } \\
\text { vadesi } 3 \text { aydan } 1 \text { haftaya indirilmiştir. }\end{array}$ & Döviz piyasası likiditesini sınırlamak \\
\hline Eylül, Kasım 2010 & $\begin{array}{l}\text { Türk lirası zorunlu karşılık oranları \% } 6 \text { 'ya } \\
\text { yükseltilmiştir. Türk lirası zorunlu karşıllıklara faiz } \\
\text { ödenmesi uygulamasna son verilmiştir. }\end{array}$ & Kredi genişlemesini sınırlamak \\
\hline Kasım 2010 & $\begin{array}{l}\text { Politika faiz oranı indirilerek, gecelik borçlanma ve } \\
\text { borç verme faiz oranları arasındaki koridor } \\
\text { genişletilmiştir. }\end{array}$ & Sermaye girişlerinin vadesinin uzatılması \\
\hline \multirow[t]{2}{*}{$\begin{array}{l}\text { Aralık } \\
2011\end{array}$} & Politika faiz oran1 \%7'den $\% 6,25$ 'e düşürülmüştür. & $\begin{array}{l}\text { Yabanc1 } \\
\text { göstergelerle dengeli seyretmesini sağlamak }\end{array}$ \\
\hline & $\begin{array}{l}\text { Gecelik faiz oranlarının politika faiz oranlarından } \\
\text { daha düşük seviyede oluşmasına izin verilerek aşağı } \\
\text { yönlü oynaklık sağlamak amacıyla gecelik borçlanma } \\
\text { faiz oranı düşürülerek faiz koridoru genişletilmiştir. }\end{array}$ & $\begin{array}{l}\text { Kısa vadeli yabancı sermaye girişini } \\
\text { sınırlamak }\end{array}$ \\
\hline Ocak, Mart, Nisan 2011 & Zorunlu karşılık oranları kademeli olarak artırılmıştır. & $\begin{array}{l}\text { Enflasyon üzerinde beliren yukarı yönlü } \\
\text { riskleri sinırlamak }\end{array}$ \\
\hline Nisan 2011 & $\begin{array}{l}\text { Yabancı para zorunlu karşılık oranlarında vadeye göre } \\
\text { farklılaştırmaya gidilmiş, Türk lirası kısa vadeli } \\
\text { zorunlu karşıl1k oranları sınırlı oranda artırılmıştır. }\end{array}$ & $\begin{array}{l}\text { Ülkeye giriş yapan kısa vadeli yabancı } \\
\text { i sermayenin vadesinin uzatılması }\end{array}$ \\
\hline
\end{tabular}

Kaynak: TCMB Y1ll1k Raporu 2010-2011

Tabloya bakıldığında; TCMB'nin 2010 yılında, fiyat istikrarının yanında, likidite bolluğu nedeniyle yüksek boyutlarda olan kredi artışının sınırlandırılması, iç ve dış talepte ortaya çıkan ayrışmanın azaltılması ile bunun finansmanında kullanılan yabancı sermayenin vadesinin uzatılması ve döviz piyasasında yaşanması olası dalgalanmanın azaltılması hedeflerine odaklandığı görülmektedir. 
2011 yılının ortalarından itibaren ise, özellikle Euro bölgesindeki kamu borcu sorunlarındaki artışla risk iştahı bozulmaya başlamıştır. Ekonomiye yönelik belirsizliklerin artması gelişmekte olan ülkelere olan sermaye akışında önemli bir azalış yaratmıştır. Bu dönemde TCMB, faiz koridorunu daraltarak kısa vadeli faizlerin dalgalanmasını azaltmıştır. Bu sayede, belirsizliğin azaltılması sayesinde sermaye hareketlerindeki çıkışa belirli bir sınır getirilmesiamaçlanmıştır (Kara, 2012: 16).

2012 yılında küresel ekonominin beklenti üstü yavaşlaması, ticari açıdan en büyük ortağımız AB'nin krizde oluşu, jeopolitik risklerdeki artış ve bütün etkenlerin reel ve finansal sektörü negatif olarak etkilemesiylegerçekleşen büyüme hedeflenenin aşağısında gerçekleşmiştir. Türkiye bu dönemde öncelikli olarak büyümeden taviz vererek kontrol altına alınmış bir cari açık ve finansal istikrar hedeflemiştir. Diğer bir deyişle, ekonomide yumuşak iniş (softland) hedeflenmiştir. Ekonomi yönetiminin amacı; cari açığı kontrol edebilmek, iç ve dış talep dengesini sağlamak, enflasyondaki artışı durdurmak ve bunların yanısıra kabul edilebilir bir hızda büyümektir ve bu dönemde amaca ulaş1lmıştır (Ergün, 2013:13).

Türkiye, Amerika Merkez Bankası (FED) ve Avrupa Merkez Bankası gibi dünya çapında etken olan kuruluşların ekonomiyi canlandırmak için yaptıkları parasal genişleme politikaları neticesinde artan likidite ve Fitch ve Standard \&Poor's gibi dünya genelinde kabul görmüş derecelendirme kuruluşlarının not artırım kararları gibi dış etmenler ile 2012 yılını bir krize maruz kalmadan dahası önemli kazanımlar elde ederek geçirmiştir. Yapılan araştırmalar kredi notu yatırım yapılabilir seviyeye yükseltilen ülkelerde büyümenin ivme kazandığını, küresel doğrudan yatırımların artış eğilimine girdiğini göstermektedir (Ergün, 2013: 15).

2013 yılı Mayıs ayındansonraki dönemde ise küresel para politikalarına yönelik gelişmeler finans piyasalarındaki hareketlerde belirleyicikonumda olmuştur.Bu dönemde küresel düzeyde hemen hemene bütün finansal varlıklarda yeniden fiyatlama yaşanmış ve gelişmekte olan ülkelere yönelik portföy akımlarında çıkışlar gözlenmiştir. Bu süreçte TCMB, 1 haftalık repo faiz oranı, faiz koridoru, Türk lirası ve yabancı para likidite politikaları ve zorunlu karşı1ık araçlarını etkin kullanarak küresel dalgalanmanın Türkiye ekonomisine yansıttığı negatif etkilerini sınırlamaya ve enflasyonda gözlemlenen bozulmayı çözmeye dair politikalar uygulamıştır(TCMB, 2015: 4).

Küresel para politikalarına yönelik belirsizliklerin döviz piyasası üzerindeki etkilerini sınırlandırmak ve finansal sistemi desteklemek için döviz likiditesini düzenleme amaçlı tedbirler alınmıştır. 2014 yılı sonundan bu yana bankaların Döviz Depo Piyasası'nda kendilerine tanınan borçlanma limitleri düzeyinde TCMB'den alabilecekleri döviz depolarının faiz oranlarını aşamalı olarak azaltan TCMB, buna ilaveten küresel para politikalarının normalleşme sürecinden öncesi ve sonrası uygulanılması olası olan politikalara yönelik sunulan yol haritasında gösterildiğigibi, bankaların TCMB gözetimindeki döviz ve efektif piyasalarında işlem yapma sınırlarını artırmıştır. Böylelikle bankalara ayrılan depo limitleri ile ROM dahilindeTCMB'de var olan altın ve döviz varlıklarının toplamının bankaların gelecek 1 yıldaki yurt dışı borç ödemelerinin hepsini karşılayabilecek düzeye erişmesi sağlanmıştır. Aynı zamanda bu süreçte, küresel finansal piyasalardaki dalgalanmalara karşı döviz satım ihalelerinin esnekliği yükseltilmiştir. Bankacılık sektörü için önemli olan bu düzenlemeler, güvence sağlamakta ve bu sektörde gerçekleşebilecek herhangi bir dış finansman şokuna karşı direnci artırmaktadır (TCMB, 2015: 3-4). 
2015 yılı genelinde gözlemlenen sık1 para politikası neticesinde ortalama fonlama faizi aşamalı bir şekilde artırılmış ve bankalararası gecelik repo faizlerinin faiz koridorunun üst bandında oluşması sağlanmıştır. Makroihtiyati önlemler ve para politikasındaki sıkı duruş 2015 yılında enflasyonun yükselişini sınırlamıştır. 2015 yılı genelinde başta petrol olmak üzere döviz cinsinden ithalat fiyatları da enflasyonu sınırlayıcı yönde etki yapmıştır. Buna rağmen gıda fiyatlarındaki artışa ve döviz kurundaki değer kaybının gecikmeli etkilerine bağlı olarak yıl boyunca enflasyon, hedefin belirgin olarak üzerinde seyretmiştir. 2015 yılının son çeyreğinde politika duruşu enflasyon görünümüne karşı sık1, döviz likiditesinde dengeleyici ve finansal istikrarı destekleyici yönde belirlenmiştir. Sıkı para politikası duruşunun ve alınan makroihtiyati önlemlerin etkisiyle kredilerin yıllık büyüme hızlarının uygun seviyelerdeolması ve ticari kredilerin tüketici kredilerine nazaran daha yüksek bir ivme ile gelişmeye devam edişi ekonominin dengelenmesine katkı sağlamaktadır (TCMB, 2015: 4-5).

Türkiye'ye ait son ekonomik verilerin bazıları aşağıdaki grafiklerde (Grafik 1-2-3) gösterilmektedir:

\section{Grafik 1: Türkiye Yıllık Tüketici Enflasyonu (2011-2016)}

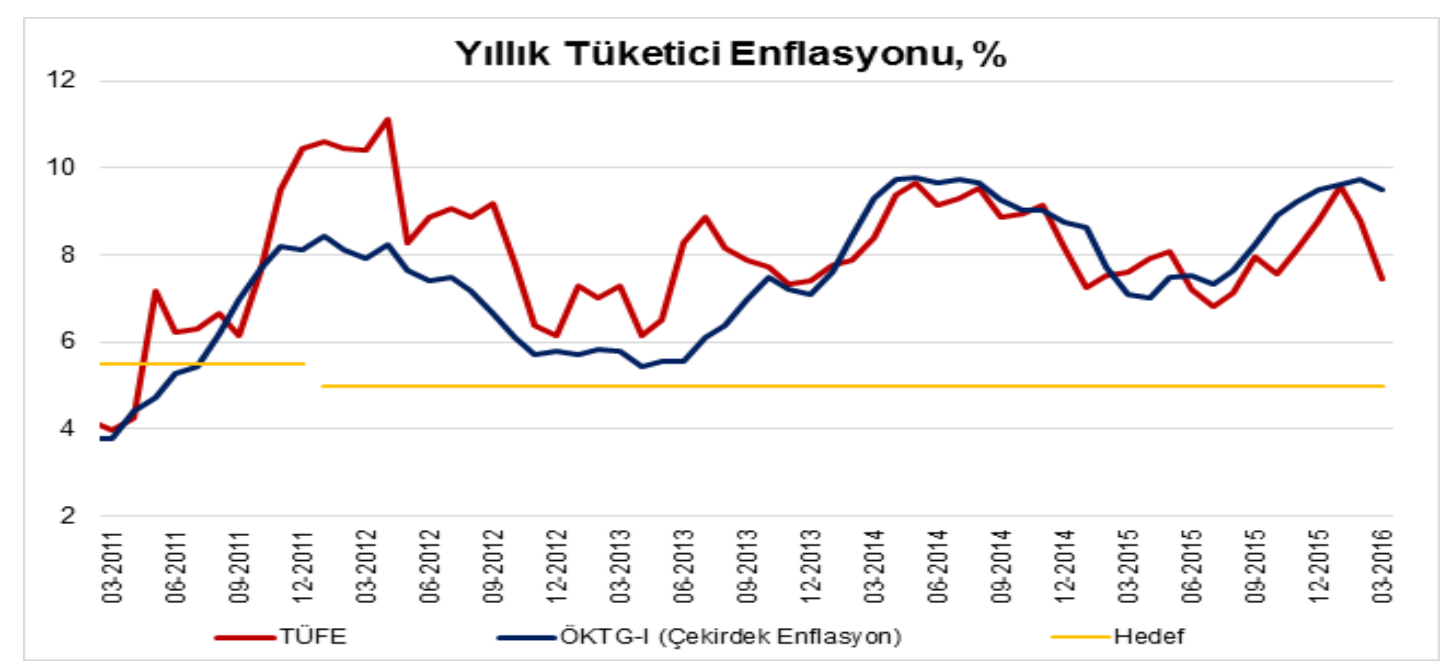

Kaynak:http://www.iso.org.tr/projeler/arastirmalar/makro-ekonomik-arastirmalar/guncel-ekonomikgostergeler/subatta-tufe-enflasyonu-dusus-gosterdi/ Erişim: 22.05.2016.

TCMB 27 Ocak 2016 tarihinde yayınladığı Enflasyon Raporu'nda yılsonu enflasyon tahminini ortas1 yüzde 7,5 olmak üzere yüzde 6,1 ile yüzde 8,9 aralığında belirlemiştir. TCMB tarafindan düzenlenen Beklenti Anketi'ne göre, 2016 yllsonu enflasyon tahmini yüzde 8,29'dur ve bir önceki ankete kıyasla 0,19 puan düşüş göstermiştir (http://www.iso.org.tr/projeler/arastirmalar/makroekonomik-arastirmalar/guncel-ekonomik-gostergeler/subatta-tufe-enflasyonu-dusus-gosterdi/). Erişim: 22.05.2016. 


\section{Grafik 2:Türkiye Cari Denge (2011-2016)}

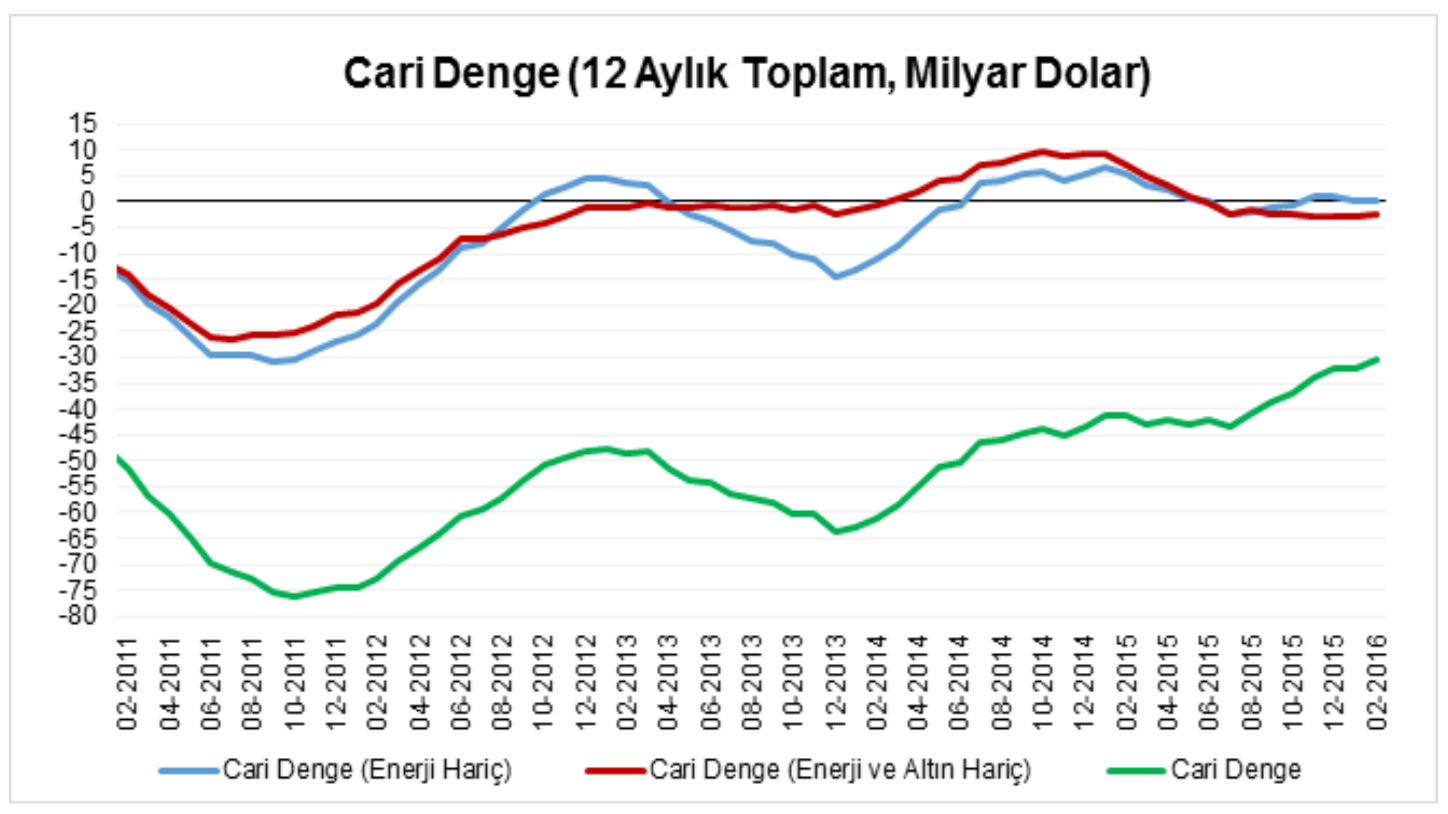

Kaynak: TCMB.

2015 milli gelir verilerinin açıklanması ile birlikte 2015'te cari açık GSYH oranı yüzde 5,5'ten yüzde 4,5'e gerilemiştir. Mevcut göstergelerin yanı sıra enerji fiyatlarının bir süre daha düşük seviyelerde kalacağı beklentisi, bu yıl yüzde 4 civarında bir cari açık/GSYH oranının gerçekleşmesinin mümkün olduğunu göstermektedir.2016 Şubat ayı verileri, cari açıktaki gerilemenin düşük emtia fiyatları sayesinde devam ettiğini göstermektedir. Yılın ilk 2 ayında (Ocak-Şubat) toplam cari açık yıllık bazda yüzde 28,3 gerilerken çekirdek (altın ve enerji hariç) cari açık da yüzde 23,8 düşüşle 1,2 milyar dolara indiği görülmektedir. (http://www.iso.org.tr/projeler/arastirmalar/makro-ekonomik-arastirmalar/guncel-ekonomikgostergeler/yillik-kumulatif-cari-acik-55-yilin-en-dusuk-seviyesinde/) Erişim: 22.05.2016. 


\section{Grafik 3: Türkiye Büyüme Oranları (2011-2015)}

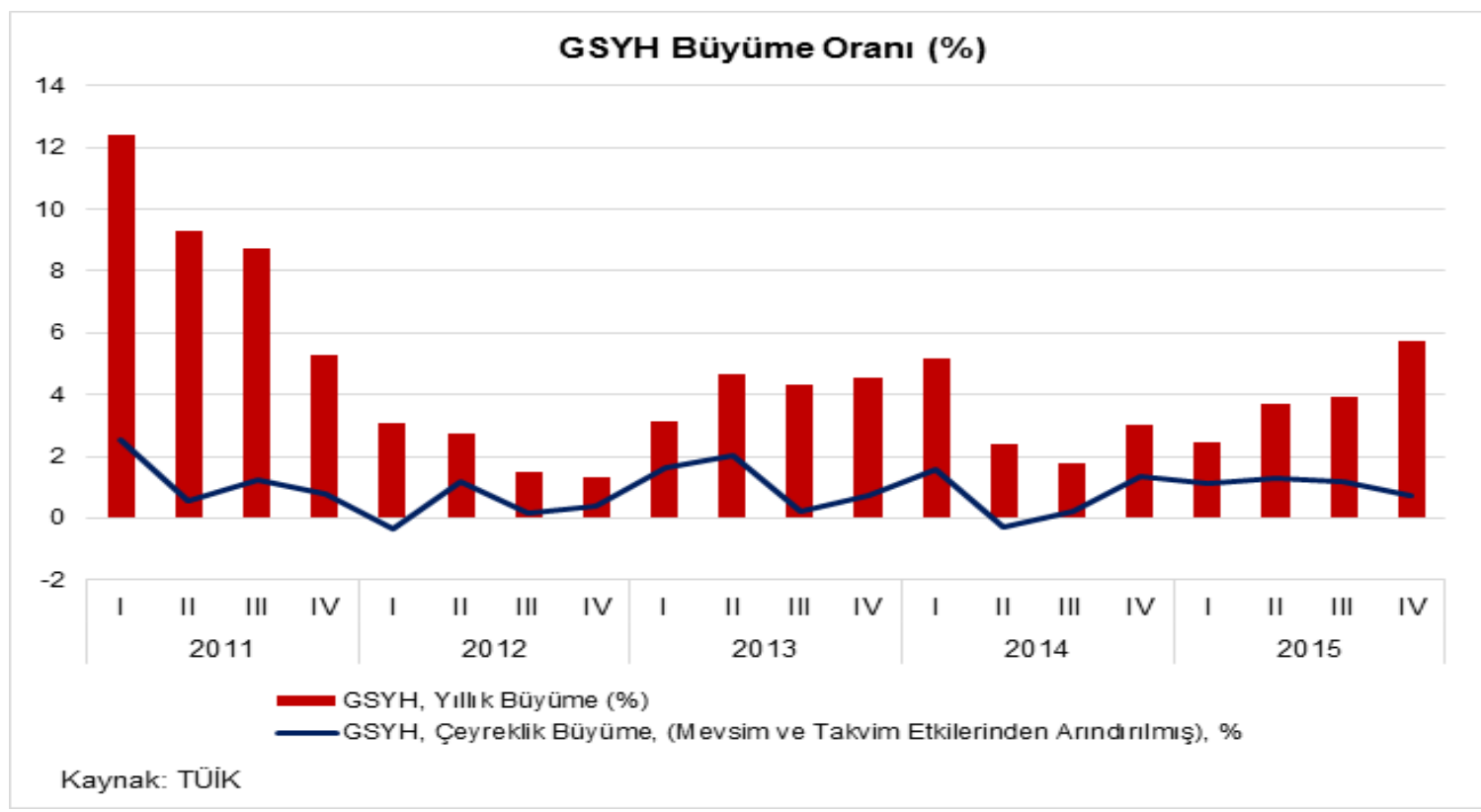

Türkiye İstatistik Kurumu (TÜIK) tarafından açıklanan verilere göre Türkiye'nin gayri safi yurtiçi hasılası (GSYİH) sabit fiyatlarla 2015'in dördüncü çeyreğinde 2014'ün aynı çeyreğine göre yüzde 5,7 oranında artış göstermiştir. Böylece 2015 yılının tamamında GSYH büyüme oranı yüzde 4 olarak gerçekleşmiştir. Açıklanan veriyle birlikte 2014 yılı büyüme oranı da yüzde 2,9'dan yüzde 3'e revize edilmiştir.

2015'in son çeyreğinde büyümenin hem harcamalar hem de üretim tarafında önceki döneme göre güçlendiği görülmektedir. Bu gelişmede takvim etkilerinin yanı sıra özellikle seçim sürecinin geride kalmasıyla nispeten azalan belirsizliğin yatırımlara olumlu yansıması, hanehalkı tüketiminin hızlanması, kamu harcamalarının büyümeye katkısının güçlenmesi, AB'ye olan ihracatın canlanması ve petrol başta olmak üzere emtia fiyatlarının düşüş göstermeyi sürdürmesi etkili olmuştur. 2015'in genelinde ise küresel büyümedeki yavaşlamanın büyümeyi dış talep yönünden zayıflattığı görülmektedir. Buna rağmen özel tüketimin canlı kalması, yatırımların ise özellikle kamu katkısıyla büyümeye geçiş yapması, geçenseneye göre GSYH artışındaki hızlanmanın altında yatan temel etkenler olmuştur (http://www.iso.org.tr/projeler/arastirmalar/makro-ekonomik-arastirmalar/guncelekonomik-gostergeler/2015te-buyume-yuzde-4-oldu/ ) Erişim: 22.05.2016.

\section{Değerlendirme}

Bu çalışmada 2001-2015 döneminde uygulanan para politikalarının Brezilya, Hindistan, Endonezya, Güney Afrika ve Türkiye olmak üzere beş ülkeden oluşan ve "Kırılgan Beşli" olarak adlandırılan ülkeleri nasıl etkilediği incelenmiştir. İncelerken ülkelerin, cari açık/GSYİH oranları ile büyüme ve enflasyon oranları ele alınmıştır.

Cari açı/GSYİH oranı değerlendirildiğinde, kırılgan beşli içerisinde cari açık/GSYİH 
oranında en kırılgan ülkenin, enerji ihtiyacının büyük bölümünü dışarıdan alması, yarı mamul mal ithalatı ve insanların ithal ürün isteği sebebiyle Türkiye olduğu ve 2011 yılında oranının \%10'a yakın olduğu görülmektedir. Bu oran daha sonra gerilemeye başlamış olsa da hala yeterli seviyede olmadığı görülmektedir.

Ülkelerin büyüme oranlarına bakıldığında, kriz sonrasında tüm ülkelerin büyümelerinde bir düşüş görülmektedir. Hatta bazılarının negatif değerler aldığı dikkat çekmektedir.Krizden sonra yaşanan büyümenin en fazla olduğu ülkenin Hindistan olduğu görülmektedir. Ardından ise Endonezya gelmektedir. Bu sıralamada en sonuncu ise Güney Afrika'dır. Kırılgan beşli ülkeleri arasında kriz sonrası en fazla büyüme oranına yine Hindistan sahiptir.

Enflasyon oranları incelendiğinde ise, kırılgan beşli ülkeleri içerisinde yıllara bakılarak en iyi enflasyon değerlerinin Brezilya'da olduğu görülmektedir. Brezilya bu değerleri uyguladığı yüksek reel faiz politikasına borçludur. Endonezya'nın ve Türkiye'nin özellikle bazı senelerdeki yüksek enflasyon oranının sebebi ise reel sektörün üretim gücünün zayıf olmasıdır.

2008 Küresel Ekonomik Krizine bakıldığında, ülkelerin krizlere karşı uyguladığı politika tedbirlerinin zamanlamasının ve politika araçlarının doğru seçilmesinin krizlerin etkisinin azaltılmasında ve ekonominin güçlenmesinde ciddi bir öneme sahip olduğu görülmektedir. Türkiye için genel bir değerlendirme yapılacak olursa; Türkiye'nin bulunduğu konumu açısından ve para piyasalarında etkin sıcak para hareketlerinden dolayı özellikle ekonomik açıdan krizin etkisini yakından hissettiği görülmektedir (Soydal, 2010:65-66). 2002-2015 yılları arasında Türkiye'nin başta enflasyon hedeflemesi olmak üzere uyguladığı politikalar sayesinde önemli bir ekonomik ilerleme kaydettiğini söyleyebiliriz. Ayrıca hedeflemelerinin de çoğunlukla gelişmelerle doğru yönde gittiği söylenebilir.

Bunların yanısıra Türkiye'de gözlemlenen jeopoliti krisklere, Güneydoğu Anadolu Bölgesi'ndeki artan terör faaliyetlerine, Türkiye genelini tehdit eden IŞİD, diğer bir adıyla DAEŞ diyerek adlandırılan terrorist örgütünün eylemlerine, göçmen sorununa, 7 Haziran seçimlerinde bir hükümetin kurulamamasına ve siyasi belirsizlikler gibi tüm olumsuzluklara ragmen Türkiye kırılgan beşli içerisinde gösterilen ülkeler arasında özellikle büyüme, cari işlemler açığı enflasyon gibi temel makro ekonomik göstergelerin birçoğunda beklenen den daha olumlu bir ekonomik görünüm arzetmiştir.

Türkiye'nin ekonomik açıdan direncinin arttığı, olası bir siyasi belirsizlik durumunda bile ekonomik anlamda dirençli olduğu hatta 15 Temmuz akşamında planlanan darbe girişimine rağmen finansal sistemin dayanıklılığının ne kadar güçlü olduğu, darbe sonrası açıklanan finansal piyasalar ve döviz kuru oranları ile test edilmiştir. 15 Temmuz'dan sonra Türkiye'de bono piyasasında sadece 20 baz puanlık bir artış olmuş, darbe girişiminin ertesi günü halk tarafından dövize ciddi bir talep olmamış ve faizler 10.5-11.5 aralığında seyretmiştir. Darbe sonrası piyasalarda da çok büyük bir sıçrama olmamıştır. 11 Eylül 2001 saldırısı sonucu ABD'de ekonominin felç olduğu ve bir yıl içerisinde 1.8 milyon kişinin işini kaybettiği, ayrıca borsadaki kaybın 1.4 trilyon doları bulduğu düşünülürse Türkiye'nin makroekonomik açıdan özellikle son senelerde önemli bir istikrar sağladığı ve finansal kırılganlığının da azaldığı söylenebilir. 
ABD'deki seçimler sonucunda Donald Trump'ın sürpriz galibiyeti, ekonomi konusundaki korumacı söylemleri ve FED'in Aralık ayındaki olası faiz artırım sinyalleri tüm küresel ekonomiyi derinden etkilemiştir. Bu nedenle Türkiye'de özellikle döviz piyasasında dolar lehine yukarı yönlü önemli bir ivme gerçekleşmiştir. Bunun sonucunda TCMB uzun bir aradan sonra faiz artırımına gitmek zorunda kalmıştır. 


\section{KAYNAKÇA}

BUSSIERE, M. and Fratzscher, M.(2006). Towards a New Early Warning System of Financial Crisis, Journal of International Money and Finance, Vol:25, p.953973.

ÇAN, H. ve Dinçsoy M.O. (2016). Kırılganlık Göstergeleri ve Kırılgan Beşli Ülkeleri Üzerine Bir İnceleme, Akademik Sosyal Araştırmalar Dergisi, Y11: 4, Sayı: 22, ss. 199-217.

ERGÜN, K.Ö. (2013), 2012: Ekonomide Yumuşak İniş Y111, Uzman Bakış, Y11 1, sayı 1.

FREUND, C. (2005). Current Account Adjustment in Industrial Countries. Journal of International Money and Finance, 24(8), 1278-1298.

GÜR, N. (2014). Bir Uluslararası Algı Oluşturma Çabası Olarak “Kırılgan Beşli” Kavramı, Seta Perspektif. Say1 49.

http://www.iso.org.tr/projeler/arastirmalar/makro-ekonomik-arastirmalar/guncel-ekonomikgostergeler/yillik-kumulatif-cari-acik-55-yilin-en-dusuk-seviyesinde/Erişim: 22.05.2016.

http://www.iso.org.tr/projeler/arastirmalar/makro-ekonomik-arastirmalar/guncel-ekonomikgostergeler/2015te-buyume-yuzde-4-oldu/ Erişim: 22.05.2016.

http://www.iso.org.tr/projeler/arastirmalar/makro-ekonomik-arastirmalar/guncel-ekonomikgostergeler/subatta-tufe-enflasyonu-dusus-gosterdi/ Erişim: 22.05.2016.

http://www.mahfiegilmez.com/2013/11/krlgan-besli.html. Erişim: 10. 07.2016.

IIF ( 2014). Global Economic Monitor.

IMF (2016). World Economic Outlook Report.

KARA, A.H. (2012). KüreselKrizSonrası Para Politikası, TCMB ÇalışmaTebliği 12/17.

MISHKIN, F.S. (2006). Para PolitikasıveTeorisi. (Çev. İlyasŞıklar, AhmetÇakmak, SuatYavuz). Ankara: BilimTeknikYayınevi.

ÖZER, M. O. (2014). KüreselKrizSırasındaTürkiye'deUygulanan Para Politikaları, YüksekLisansTezi, İstanbul ÜniversitesiSosyalBilimlerEnstitüsüİktisat Ana Bilim Dalı, İktisatTeorisiBilim Dalı, İstanbul.

SOYDAL, H. (2010). YeniEkonomi (Kuantum-nöroekonomi). PaletYayınları, Konya.

TCMB (2010) Y1ll1kRapor 2010.http://www.tcmb.gov.tr.html.

TCMB (2011) Y1ll1kRapor 2011.http://www.tcmb.gov.tr.html.

TCMB (TürkiyeCumhuriyetMerkezBankası). (2015). 2016 Yılı Para veKurPolitikası, Ankara.

VURAL, U. (2013). Geleneksel Olmayan Para Politikalarının Yükselişi, Türkiye Cumhuriyet Merkez Bankas ıIlletişim ve Dış İlişkiler Genel Müdürlüğü, Uzman Yeterlilik Tezi, Ankara. 